\title{
Bone Resorption in the Skull of Mustela vison
}

\author{
RESORBCJA KOSCI CZASZKI U NORKI AMERYKANSKIEJ
}

Øystein WIIG

\begin{abstract}
Wiig Ø., 1982: Bone resorption in the skull of Mustela vison. Acta theriol., 27, 24: 358-360 [With 1 Table]

Examination was made of the decrease of the postorbital constriction with age in 68 skulls of wild mink, Mustela vison Schreber, 1777, from Southern Norway. The decrease in the mean of the measurement from juvenile to adult age was highly significant $(P<0.01)$ in both sexes. The decrease was described to resorption of bone in the postorbital area to give way for increase of the anterior part of the temporal muscle with age and thus strengthen the force in the fully opened jaw.
\end{abstract}

[Museum of Zoology, University of Bergen, N-5014 Bergen, Norway]

\section{INTRODUCTION}

Cranial measurements of mammals are usually supposed to increase with age until the skull is fully grown. The postorbital constriction, however, is shown to decrease with age in several mustelid species (Pohle, 1919 ; Lechleitner, 1954 ; Hysing-Dahl, 1959 ; Buchalczyk \& Ruprecht, 1977).

Hysing-Dahl (1959) presumed that the decrease of the postorbital constriction in the otter, Lutra lutra (Linnaeus, 1758), is due to muscle increase. Pohle (1919) proposed that this decrease is a process of resorption of bone. However, the recorded decrease is based on comparisons of samples of the different age classes. The decrease may thus also be an effect of decrease at the population level brought about by a selective advantage and thus a higher survival rate of specimens with little postorbital constriction.

In the present study these two explanations for the occurrence of decrease of the postorbital constriction with age and its anatomical significance in wild mink, Mustela vison Schreber, 1777, are discussed based on a sample for Southern Norway.

\section{MATERIAL AND METHODS}

A total of 27 juvenile ( 17 males and 10 females) and 41 adult (20 males and 21 females) skulls were used. The minks were caught in Southern Norway mainly in 1957 and 1958 and are in the possession of Museum of Zoology, University of Bergen.

The skulls were described as adults when all their sutures were closed, which seemed to involve specimens older than eight months (Wiig \& Lie, 1979). The measurement was taken by calliper and recorded to the nearest $0.05 \mathrm{~mm}$.

Wiig \& Lie (1979) have recorded the geographical variation in Southern Norway 
of 15 cranial measurements of adult wild mink. The variation of the postorbital constriction between Eastern Norway and Trøndelag were insignificant. These samples were consequently pooled and used in the present work. Corresponding samples of juvenile skulls were also used.

Highly significant sexual dimorphism in the present measurement have been demonstrated (Wiig, 1978); the sexes were consequently treated separately.

\section{RESULTS AND DISCUSSION}

In each sex the mean of the postorbital constriction in juveniles is significantly larger than in adults $(P<0.01)$. Also the minimum and the maximum values are larger in the juveniles. The range of the measurement and the coefficient of variation are, however, smallest in the juveniles of both sexes (Table 1).

Table 1

Number of specimens (n), and minimum (Min.) and maximum (Max.) values, mean $(\overline{\mathrm{x}})$, standard deviation $(\mathrm{s})$, and coefficient of variation $(\mathrm{v})$ of the postorbital constriction in a sample of wild mink, Mustela vison, from Southern Norway.

\begin{tabular}{llllllll}
\hline & & $\mathrm{n}$ & Min. & Max. & $\overline{\mathrm{x}}$ & $\mathrm{s}$ & $\mathrm{v}$ \\
\hline \multirow{2}{*}{ Males } & juv. & 17 & 12.20 & 14.05 & 13.200 & 0.534 & 4.0 \\
& ad. & 20 & 11.00 & 13.85 & 12.359 & 0.741 & 6.0 \\
& juv. & 10 & 11.65 & 13.60 & 12.350 & 0.603 & 4.9 \\
& ad. & 21 & 9.60 & 12.75 & 11.180 & 0.948 & 8.5 \\
\hline
\end{tabular}

The variation of the postorbital constriction between juvenile and adult wild mink is presumed to reflect true variation between the age classes.

If decrease of the postorbital constriction is a characteristic feature of the population only and not of the single individual, the range of the measurement in the juveniles should include the range in the adults. Lower survival rate of individuals with broad postorbital constriction should thus tend to lower the maximum value and the coefficient of variation of the adults. This is not in accordance with the present results.

If there is a resorption of bone in the postorbital region this would probably continue after the closure of the sutures, because such resorption is not dependent of open sutures. The range and the variation of the postorbital constriction in adults might thus increase as the measurement of the single individual decrease as found in the present material.

Pohle (1919) based his explanation of resorption in the otter on the spongy looking surface of the juvenile skulls in the postorbital area, which in his opinion indicated a high degree of resorption. This spongy looking surface is characteristic of the present juvenile mink skulls but is also present in some of the adults. 
The decrease of the postorbital constriction with age in the wild mink seems thus to be caused by resorption of bone.

Hysing-Dahl (1959) presumed that the decrease of the postorbital constriction was due to muscle increase. According to Ewer (1973) the weak zygoma typically found in small mustelides, indicates that the main part of the masticatory work is performed by the temporalis muscle. Most of this muscle originates from the braincase roof. In the otter the temporalis constitutes almost $80 \%$ of the total mass of the jaw musculature and the masseter, which originates on the zygoma, less than $20 \%$ (Schumacher, 1961). In most carnivores the anterior fibres of the temporalis together with the zygomatico-mandibularis muscle are responsible for exerting the main force when the jaws are fully open (Ever, 1973). But the weak zygoma in the small mustelides must also indicate that the zygomatico-mandibularis muscles is reduced. Most of the work done when the jaws are fully open must then be performed by the anterior part of the temporalis, which mainly originates in the postorbital region. A decrease of the postorbital constriction will consequently give way for an increase of the anterior part of the temporalis muscle, and thus an increase of the force in the fully opened jaw. This explanation is also assumed to be valid for such decrease in other mustelid species.

Wallace Park \& Nowosielski-Slepowron (1980) found indications of broadening of the postorbital constriction with age in ranch breed mink. But with little masticatory work to do, captive animals do not develop the diet of $C$. poensis but despite the small number of samples these and their skulls may therefore be abnormal (Ewer, 1973).

Acknowledgements: The auther is indebted to Dr. T. Andersen for valuable comments on the manuscript.

\section{REFERENCES}

Buchalczyk T. \& Ruprecht A. L., 1977: Skull variability of Mustela putorius Linnaeus, 1758. Acta theriol., 22: 87-120. - Ewer R. F., 1973: The carnivores. Weidenfeld and Nicolson: 1-494. London. - Hysing-Dahl C., 1959: The Norwegian otter Lutra lutra (L.), a craniometric investigation. Univ. i Bergen Arb. Naturv. Rek., 1959, 5: 1-44. - Lechleitner R. R., 1954: Age criteria in mink Mustela vison. J. Mammal., 35: 496-503. - Pohle H., 1919: Die Unterfamilie der Lutrinae. Arch. Naturgesch., 85: 1-247. - Schumacher G. H., 1961: Funktionelle Morphologie der Kaumuskulatur. Fischer: 7-474. Jena. - Wallace Park A. \& Nowosielski-Slepowron B. J. A., 1980: Aspects of skull and dentition morphology of the mink (Mustela vison). Acta Morphol. Neerl.-Scand., 18: 47-65. - Wiig Ø., 1978: Kraniologisk undersøkelse av villmink (Mustela vison Schreber). Univ. of Bergen: 1-47. Bergen. [Unpubl. cand. real. thesis]. - Wiig Ø. \& Lie R. W., 1979: Metrical and non-metrical skull variations in Norwegian Wild Mink (Mustella vison Schreber). Zool. Scr., 8: 297-300.

Accepted, January 27, 1982. 


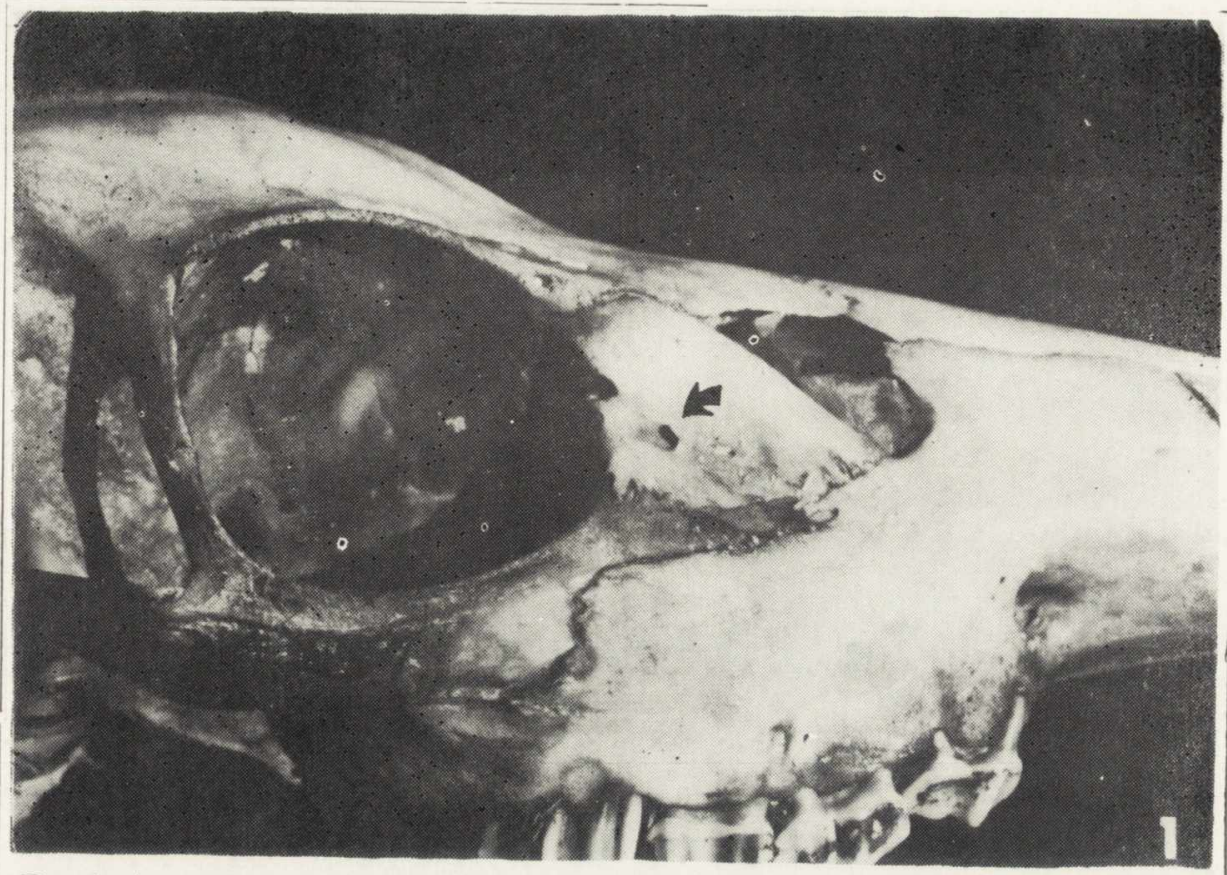

Fig. 1. Anomaious lacrimal orifice in a sika deer (Cervus nippon). Note anterior displacement of lower orifice.

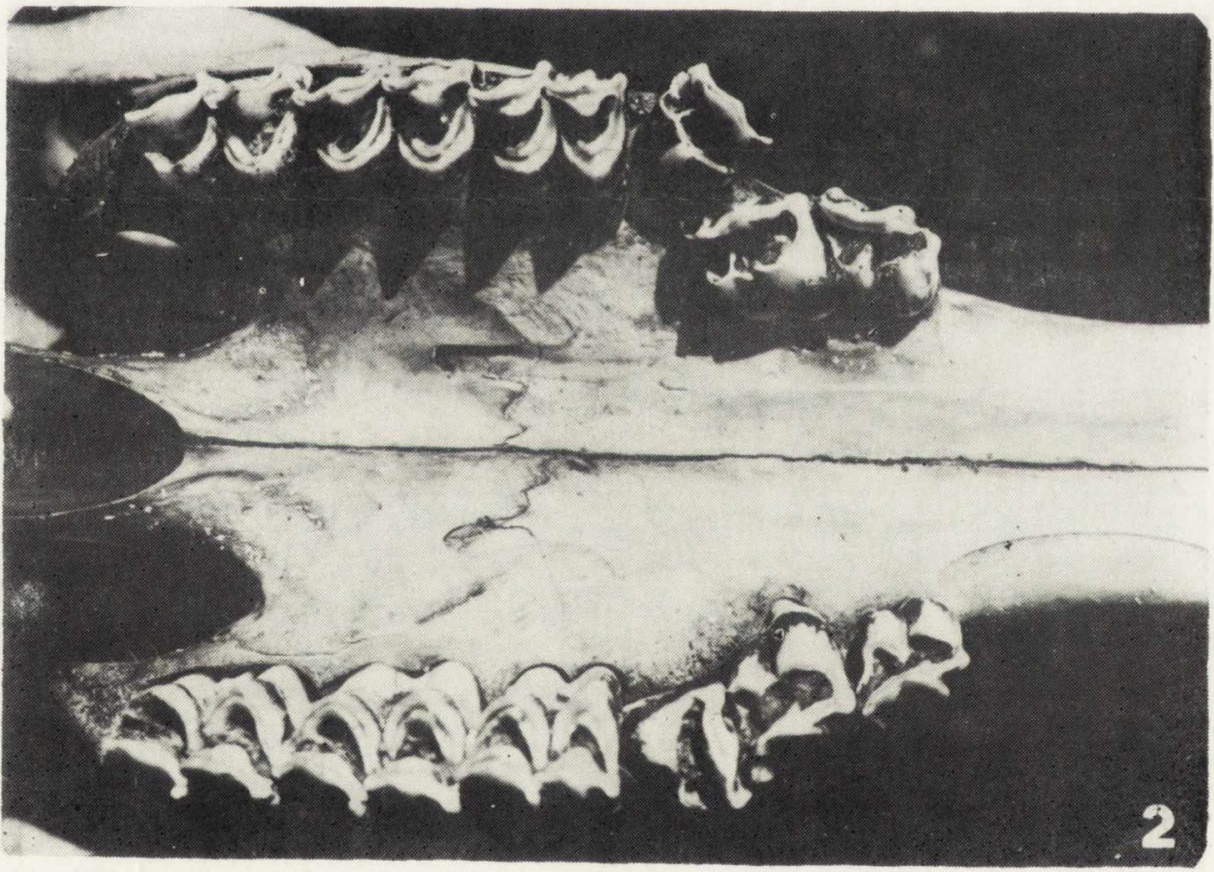

Fig. 2. Irregular placement of maxillary premolars in a sika deer (Cervus nip yon). 


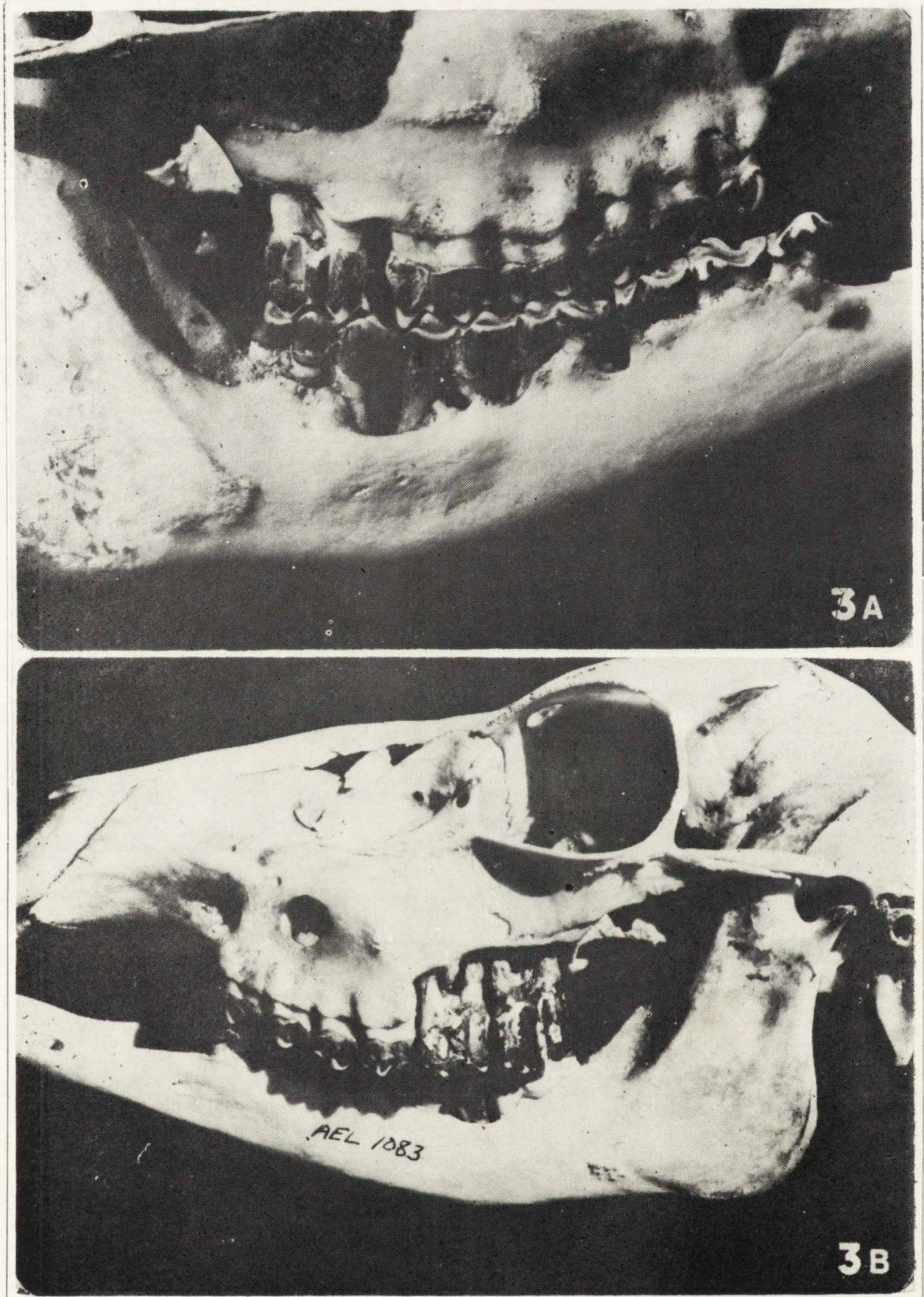

Fig. 3. A) Periodontal disorder in a 9-year old female sika deeer (Cervus nippon), and $\mathrm{B}$ ) in a 6 -year old female. 